\title{
PADI4 and tumourigenesis
}

\author{
Xiaotian Chang* and Kehua Fang
}

\begin{abstract}
PADI4 post-translationally converts peptidylarginine to citrulline, a process called citrullination. Studies have demonstrated the high expression of PADI 4 in various malignant tumour tissues. PADI 4 is also expressed at high levels in the blood of patients with some malignant tumours. Thus far, citrullination of histone, cytokeratin, antithrombin and fibronectin have been confirmed to be involved in abnormal apoptosis, high coagulation, and disordered cell proliferation and differentiation, all of which are main features of malignant tumours. PADI 4 is expressed in CD34+ stem cells in normal tissues, and many more CD34+ cells expressing PADI4 are present in tumour tissues. These findings suggest that PADI4 may play an important role in tumourigenesis.
\end{abstract}

\section{Introduction}

Peptidylarginine deiminase (PAD) can catalyse peptidyl arginine to citrulline in the presence of $\mathrm{Ca}^{2+}$ ions, a reaction known as citrullination, which leads to the posttranslational modification of proteins. Genes encoding PAD family members, including PADI1, PADI2, PADI3, PADI4, and PADI6, cluster at human chromosome position $1 \mathrm{p} 36.13$. The high sequence identity of the C-terminal domains of all PADs suggests that their structures are similar [1]. The expression of all of these isoforms has been detected in numerous tissues. PADI1 is found in the skin epidermis [2], PADI2 is present in various tissues including brain and muscle [3,4], PADI3 is localised in hair follicles [5], PADI4 is mainly expressed in granulocytes and monocytes [6], and PADI6 is specially expressed in embryonic stem cells and oocytes $[7,8]$. Studies have reported that PADs are involved in cell differentiation, apoptosis, nerve growth, embryonic development, and gene regulation [9]. Biochemical and immunohistochemical assays have suggested the involvement of PADI1 in the terminal differentiation of the epidermis [10], PADI2 in the myelination and citrullination of central nerve axons $[11,12]$, and PADI3 in the keratinisation of hair follicles $[3,13]$. Arginine residues frequently function as ligand recognition sites in proteins. Some enzymes that interact with negatively charged substrates or cofactors have an arginine residue as an anion recogni-

\footnotetext{
*Correspondence: changxt@126.com

1 Laboratory for Bio-Drugs of Ministry of Health, Provincial Laboratory for Modern Medicine and Technology of Shandong, Research Center for Medicinal Biotechnology, Shandong Academy of Medical Sciences, Jingshi Road 18877, Jinan, Shandong, 250062, PR China
}

tion site [14]. Therefore, it seems possible that PADs and citrullination participate in the regulation of these enzymes. In addition, PAD citrullination was suggested to modify the action of trypsin-like enzymes [15] and trypsin inhibitors [14], to interfere with intermediate filament assembly [16], and to play a role in rapid cellular turnover in tissues with secretory activity [17]. However, the physiological significance of each of the PADs has not been understood in detail.

PADI4 was initially cloned from the HL-60 cell line (human promyelocytic leukaemia cells) [6]. The protein is 663-amino acids long with a molecular weight of 74,095 $\mathrm{Da}$. The PADI4 polypeptide chain has two spherical subunits at the $N$ terminus, one $\alpha$ helix $\beta$ fold structure at the $\mathrm{C}$ terminus, and five $\mathrm{Ca}^{2+}$ ion-binding sites. The binding of $\mathrm{Ca}^{2+}$ ions to PADI4 induces conformational changes in the peptide chain that result in the formation of active sites, such that the enzyme enters its active state for the catalysis of arginine residues into citrulline residues [1]. PADI4 is predominantly expressed in blood lymphocytes and has been suggested to play a role in inflammation and the immune response [18-21]. Because PADI4 was also detected in granulocytes and macrophages induced by HL60 cells, the enzyme is believed to be involved in the differentiation and apoptosis of these cells [6]. However, little is known about the precise function and target substrates of PADI4 under physiological conditions.

PADs and citrullinated proteins are involved in the pathogenic processes of many human diseases, because citrullination tends to alter the conformation and activity of target proteins, leading to changes in physiological and biochemical activity. Rheumatoid arthritis (RA), an auto-

(c) 2010 Chang and Fang; licensee BioMed Central Ltd. This is an Open Access article distributed under the terms of the Creative ComBH 1 ed Central mons Attribution License (http://creativecommons.org/licenses/by/2.0), which permits unrestricted use, distribution, and reproduction in any medium, provided the original work is properly cited. 
immune disease, is characterised by the presence of many types of autoantibodies against citrullinated proteins in the blood of patients, indicating that citrullination plays an essential role in the autoimmune reaction and the destruction of joint tissues [22,23]. By whole genome SNP scanning, Suzuki et al. demonstrated a strong association of PADI4 with RA [24]. Chang et al. detected an elevated expression of PADI4 in the synovial membrane and synovial fluid of RA patients $[19,25]$. In addition, Mastronardi et al. detected citrullination of nucleosome histone $\mathrm{H} 3$ in the cerebral white matter of multiple sclerosis patients and demonstrated that tumour necrosis factor (TNF) $\alpha$ induced PADI4 translocation to the nucleus [26]. The citrullination of proteins appears to be abnormally increased in Alzheimer's disease, glaucoma, and neurodegeneration [27-29].

Cancer is one of the leading causes of death in humans. In recent years, our studies and others' found that PADI4 is highly expressed in a variety of malignant tumours and that it participates in the process of tumourigenesis. This review highlights PADI4 expression in tumour tissues as well as the potential role of PADI4 in the pathogenesis of cancer.

\section{Expression of PADI4 in various malignant tumours}

Tumour tissues and synovial tissues from patients with RA have a lot of common characteristics. Both tissues show abnormal cell proliferation, fibrin deposition, coagulation activity, and angiogenesis [30]. Because PADI4 is one of the genes associated with RA, we speculated that PADI4 might also play a role in the tumourigenic process. Using immunohistochemistry, quantitative PCR, and western blot analysis, we detected significant PADI4 expression in tumour cells of various malignancies, including breast carcinomas, lung adenocarcinomas, hepatocellular carcinomas, oesophageal squamous cancers, colorectal adenocarcinomas, renal cancers, ovarian adenocarcinomas, endometrial carcinomas, uterine adenocarcinomas, bladder carcinomas, and chondromas, as well as in other metastatic carcinomas. However, PADI4 was not expressed in benign leiomyomas of the stomach, uterine myomas, endometrial hyperplasias, cervical polyps, teratomas, hydatidiform moles, trophoblastic cell hyperplasias, hyroid adenomas, haemangioma, lymph hyperplasias, schwannomas, neurofibromas, lipomas, or cavernous haemangioma of the liver. Additionally, PADI4 expression was not detected in non-tumour tissues, including cholecystitis, cervicitis, and synovitis of osteoarthritis, except in certain acutely inflamed tissues such as in acute gastritis and acute appendicitis. In addition, western blot analysis detected PADI4 expression in cultured tumour cell lines including A549 (lung adenocarcinoma), SKOV3 (ovarian adenocarcinoma), and U937 (leukaemia) cells. ELISAs detected increased
PADI4 levels in the blood of patients with various malignant tumours compared to those in patients with chronic inflammation and benign tumours. PADI4 levels were also significantly associated with CEA levels, a serum marker for tumour diagnosis, in the blood of patients with gastric cancer and prostate cancer [31,32]. Recently, Lv. et al. reported the significantly increased expression of PADI4 in hepatocellular carcinomas compared to that in the surrounding healthy tissues, as determined by western blot analysis [33]. Stacey et al. conducted a genomewide SNP association study and found that common variants on rs7538876 of $1 \mathrm{p} 36$, containing the PAD locus, are significantly associated with coetaneous basal cell carcinoma but not with melanoma or pigmentation traits [34].

Many studies have investigated the tissue distribution of PADI4 in diseased tissues. In the RA synovial membrane, PADI4 was located in T cells, B cells, granulocytes, macrophages, and capillary endothelial cells [19]. PADI4 was also detected in eosinophils and neutrophils of peripheral blood cells $[18,19]$. In our study, PADI4 was demonstrated in CD34+ cells of the bone marrow and normal tissues by double immunolabelling. Although tumour cells that express PADI4 lacked CD34 signals, the enzyme is located in CD34+ mesenchymal cells in the stromal region of the tumour tissues [31]. These observations and studies by others suggest that PADI4 expression may be limited to haematopoietogenic lineage cells that originally develop from haematopoietic cells (HPCs) in the bone marrow. HPCs marked with CD34 comprise a well-characterised population of multi-potent progenitor cells that are able to self-renew and give rise to terminally differentiated haematopoietic cells, or something more specific. These stem cells can also differentiate and integrate into various tissues such as skeletal muscle, cardiac monocytes, vascular endothelium, liver, and brain $[35,36]$. Because there are more CD34+ cells expressing PADI4 in tumour tissues than in normal tissues [31], it is postulated that the development of PADI4-expressing tumour cells may be associated with the abnormal proliferation of CD34+ stem cells or their progeny. In fact, many studies have found a strong association between CD34 cells and tumourigenesis in the lung, pancreas, liver, and stomach adenocarcinomas [37-42]. Strobel et al. reported that human bone marrow cells have the ability to stimulate the growth, in a dose-dependent manner, of many types of tumour cells in vitro [43]. Hellwig et al. found that basic fibroblast growth factor (bFGF) and vascular endothelial growth factor (VEGF), both of which are increased with the progression of tumourigenesis, suppress the expression of CD34 in renal carcinoma. Such a down-regulation of CD34 adhesion molecules may allow tumour cells to escape immune surveillance [44]. Their findings may explain the disappearance of 
CD34 expression in PADI4-expressing tumour cells observed in our study.

\section{Citrullination of proteins}

PADI4 exerts post-translational modifications through the conversion of arginine to citrulline. Therefore, the identification of PADI4 substrates is helpful for understanding the pathogenic mechanisms of the enzyme during tumourigenesis.

P53 inhibits malignant transformation through the transcriptional regulation of its target genes to mediate the cell cycle and apoptosis $[45,46]$. Under normal circumstances, damaged, aging, or diseased cells increase their expression of p53, activating its downstream target genes and eventually inducing apoptosis to ensure the health of the body [47]. Studies have indicated that p53 regulates the transcription of target genes by post-translational modification of histones via methylation, acetylation, phosphorylation, ubiquitination, and citrullination $[48,49]$. Using chromosome immunoprecipitation, Yao et al. and Li et al. investigated the promoters of p53 target genes and found that over-expression of PADI4 may prevent arginine methyltransferase from methylating histone $\mathrm{H} 3$ by converting arginine residues into citrulline. As a result, the expression of p53 target genes is reduced, resulting in the disruption of cellular apoptosis and the normal cell cycle $[50,51]$. Hagiwara et al. and Cuthbert et al. also confirmed that the citrullination of histones by PADI4 antagonises arginine methylation [52,53]. Using cultured human leukaemia HL-60 cells and human acute $\mathrm{T}$ leukaemia Jurkat cells, Liu et al. found that the overexpression of PADI4 could induce the up-regulation of p53, p21, and Bax expression, resulting in cell cycle arrest and mitochondria-mediated apoptosis [54]. However, Lv et al. recently detected decreased p53 levels in tumour tissues from patients with hepatocellular carcinomas compared to the surrounding healthy tissues. They also found that the expression of p53 was obviously decreased in HeLa cells transfected with a PcDNA3.0-Flag-PADI4 plasmid, suggesting that the enzyme induces tumourigenesis by down-regulating p53 expression [33].

Cytokeratin (CK), the intermediate filament protein, constitutes the cytoskeleton and plays an important role in cellular stress, signal transduction, and apoptosis. CK, as a tumour-specific marker, displays high expression in gastric cancer, pancreatic cancer, breast cancer, urinary tract transitional cell carcinoma, and other tumour epithelial cells $[55,56]$. Omary et al. have found that the glycosylation, phosphorylation, and other post-translational modifications of CK change its solubility and other physi$\mathrm{cal}$ and chemical properties that lead to cellular apoptosis in a variety of physiological processes [57]. By immunohistochemistry and western blotting, we found that PADI4 and CK have similar distributions in the colon, oesophagus, bladder, lung, rectum, stomach and breast cancer, thyroid tumour, oesophageal squamous cell carcinoma, hepatocellular carcinoma, and other non-adenocarcinomas. Co-immunoprecipitation indicated the citrullination of CK8, 18, and 19 in tumour tissues. Following the citrullination of PADI4, CK is not digested by caspase, thereby disrupting the process of apoptosis [31]. An imbalance of apoptosis is one of the characteristics of malignant tumours.

Antithrombin (AT) is a member of the serine protease inhibitor (serpin) superfamily, and it inhibits plasma thrombin activity to maintain the dynamic equilibrium of the coagulation and anti-coagulation system. Structural changes in AT may lead to abnormal blood clotting. It is reported that approximately $90 \%$ of cancer patients are at risk of thrombosis [58]. We incubated recombinant PADI4 with human AT. Western blots and ELISA showed that the citrullination of AT decreased its ability to inhibit thrombin [59]. Recently, Ordóñez A. et al. confirmed by proteomic analysis that the citrullination of antithrombin abolished its activity. They also found that this abolition of activity was accelerated by heparin, which facilitated the citrullination of Arg393 (P1 residue). Their proteomic analyses revealed nine additional citrullines that caused a significant decrease in its electrostatic potential [60]. Using sandwich ELISA, we detected higher levels of PADI4 and citrullinated AT levels in the plasma of patients with malignant tumours, including those with breast carcinomas, hepatocellular carcinomas, lung carcinomas, oesophageal carcinomas, gastric cancer, colon cancer, rectal cancer, pancreatic cancer, ovarian carcinomas, bladder carcinomas, uterine myomas, thyroid carcinomas, and prostate carcinomas. The levels of citrullinated antithrombin were significantly associated with PADI4 levels in blood of patients with hepatocellular carcinomas, lung cancer, ovarian cancer, endometrial carcinomas, and thyroid adenomas. In addition, the levels of citrullinated AT were clearly associated with the CEA levels in the blood of patients with breast carcinomas, bladder cancer, renal cell carcinomas, and pancreatic cancer; with CA199 levels in those with gastric cancer; with CA125 levels in those with ovarian cancer; and with PSA in those with prostate cancer [32]. CEA, CA199, CA125, and PSA are tumour makers and are currently used for tumour diagnosis. These results suggest that PADI4 may be responsible for the high coagulation activity induced by the citrullination of AT in cancer patients. Studies have shown that an increase in thrombin activity can promote fibrin deposition, angiogenesis, and tumour cell invasion and metastasis, ultimately leading to the malignant proliferation of tumour cells [61].

Fibronectin (Fn) is a glycoprotein that is widely present in the extracellular matrix, plasma, and other body fluids. Structurally, it contains multiple functional domains that 
interact with the extracellular matrix, integrin receptors, and growth factors, which play important roles in cell adhesion, migration, differentiation, and proliferation. A number of studies have demonstrated an important role of $\mathrm{Fn}$ in tumourigenesis [62,63]. Our in vitro study showed that rabbit PAD may catalyse citrullination of both the cellular and serum Fn. Following citrullination, the affinity of Fn for VEGF increases, but its binding activity to integrin $\beta 1$ decreases, and Fn no longer stimulates the apoptosis of monocytes induced from cultured HL-60 cells [64]. Therefore, it is suggested that Fn may also be citrullinated by PADI4 in tumours, thus leading to tumour cell invasion, proliferation, and malignancies.

\section{Regulatory mechanism of PADI4}

To date, little is known about the mechanisms that regulate PADI4. Dong et al. found that oestrogen regulates the expression of PADI4 through both the classical and nonclassical pathways [65]. In the classical way, oestrogen binds to the oestrogen receptor to form a complex and then regulates PADI4 expression via the oestrogen response element on the promoter. In the non-classical pathway, the oestrogen-oestrogen receptor complex acts on the transcription factors AP-1, NF-Y, and SP-1, which bind to the PADI4 promoter to specifically regulate PADI4 expression. On the other hand, Cuthbert et al. found that PADI4 could suppress the expression of oestrogen-regulated genes by antagonizing the methylation of histone $\mathrm{H} 3$ on the pS2-promotors of these genes by citrullination [53]. It is possible that oestrogen regulates oestrogen-sensitive genes by a negative feedback effect via the citrullination of PADI4. Recently, Tanikawa et al. reported that p53 transactivated PADI4 through a p53-binding site located in the first intron. Furthermore, they found that the knockdown of PADI4 attenuated p53mediated growth-inhibitory activity, demonstrating the significance of PADI4-mediated protein citrullination in the p53 signalling pathway [66]. This result seems controversial in light of the findings that PADI4 disrupts the apoptotic process via the citrullination of histone $\mathrm{H} 3$ on the promoter of p53-target genes [50,51], but it is consistent with the result that over-expression of PADI4 can induce apoptosis [54].

We review the following regulatory mechanism of PADI4 by summarizing our studies and those of others (Figure 1).

\section{PADI4, a potential biomarker}

To date, a number of biomarkers have been used for tumour diagnosis. However, the specificity and sensitivity are inappropriate for large-scale surveys of tumour prognosis, because these tumour markers can only be expressed in one or several kinds of tumours. PADI4 is highly expressed in a variety of malignant tumours but is

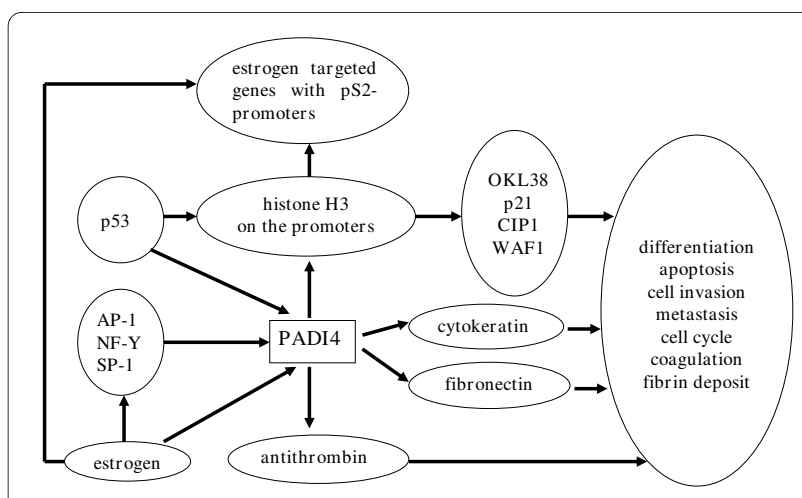

Figure 1 regulatory mechanism of PADI4 - study summary

either not expressed or is expressed at very low levels in normal tissues and benign tissues. The enzyme can be considered as an immunohistochemical barometer to distinguish tumour cells from non-tumour cells and to define the tissue structure of tumours. Because patients with various malignant tumours display an increased expression of PADI4 in their blood, and because the level of expression declines after tumour excision surgery [32], the enzyme can be used as a serum maker of tumours to compensate for some of the deficiencies in the current methods employed for tumour diagnosis. In addition, the specific nature of PADI4 expression in tumour cells makes PADI4 a potential target for cancer therapy. Hence, PADI4 could have important clinical applications; however, further research is necessary to develop this marker into a useful clinical diagnostic tool.

\section{Conclusion}

In summary, PADI4 demonstrates significant expression in various malignant tissues but maintains a low level of expression in normal and benign tissues. Studies have indicated that PADI4 may be involved in tumourigenesis via the citrullination of histone, cytokeratin, antithrombin, and fibronectin; although some studies suggest that the enzyme can induce apoptosis.

\section{Competing interests}

The authors declare that they have no competing interests.

\section{Authors' contributions}

$\mathrm{XC}$ and $\mathrm{KF}$ contributed equally to the elaboration of the review. XC is the senior author. All authors read and approved the final manuscript.

\section{Author Details}

Laboratory for Bio-Drugs of Ministry of Health, Provincial Laboratory for Modern Medicine and Technology of Shandong, Research Center for Medicinal Biotechnology, Shandong Academy of Medical Sciences, Jingshi Road 18877, Jinan, Shandong, 250062, PR China

Received: 10 November 2009 Accepted: 12 March 2010 Published: 12 March 2010 


\section{References}

1. Arita K, Hashimoto H, Shimizu T, Nakashima K, Yamada M, Sato M: Structural basis for $\mathrm{Ca}(2+)$-induced activation of human PAD4. Nat Struct Mol Biol 2004, 11:777-783.

2. Guerrin M, Ishigami A, Mechin M, Nachat R, Valmary S, Sebbag M, Simon $M$, Senshu T, Serre G: CDNA cloning, gene organization and expression analysis of human peptidylarginine deiminase type I. Biochem J 2003, 370:167-174.

3. Ishigami A, Ohsawa T, Asaga H, Akiyamab K, Kuramotoa M, Maruyama N Human peptidylarginine deiminase type II: molecular cloning, gene organization, and expression in human skin. Arch Biochem Biophys 2002, 407:25-31.

4. Watanabe K, Senshu T: Isolation and characterization of cDNA clones encoding rat skeletal muscle peptidylarginine deiminase. $\mathrm{J}$ Biol Chem 1989, 264:15255-15260

5. Kanno T, Kawada A, Yamanouchi J, Yosida-Noro C, Yoshiki A, Shiraiwa M, Kusakabe M, Manabe M, Tezuka T, Takahara H: Human peptidylarginine deiminase type III: molecular cloning and nucleotide sequence of the CDNA, properties of the recombinant enzyme, and immunohistochemical localization in human skin. J Invest Dermatol 2000, 115:813-823.

6. Nakashima K, Hagiwara T, Ishigami A, Nagata S, Asaga H, Kuramoto M, Senshu T, Yamada M: Molecular characterization of peptidylarginine deiminase in HL-60 cells induced by retinoic acid and 1alpha, 25dihydroxyvitamin D(3). J Biol Chem 1999, 274:27786-27792.

7. Zhang J, Dai J, Zhao E, Lin Y, Zeng L, Chen J, Zheng H, Wang Y, Li X, Ying K, Xie Y, Mao Y: cDNA cloning, gene organization and expression analysis of human peptidylarginine deiminase type VI. Acta Biochim Pol 2004, 51:1051-1058

8. Chavanas S, Mechin MC, Takahara H, Kawada A, Nachat R, Serre G, Simon $\mathrm{M}$ : Comparative analysis of the mouse and human peptidylarginine deiminase gene clusters reveals highly conserved non-coding segments and a new human gene, PADI6. Gene 2004, 330:19-27.

9. Chavanas S, Méchin MC, Nachat R, Adoue V, Coudane F, Serre G, Simon M: Peptidylarginine deiminases and deimination in biology and pathology: relevance to skin homeostasis. J Dermatol Sci 2006, 44:63-72.

10. Ishida-Yamamoto A, Senshu T, Eady RA, Takahashi H, Shimizu H, Akiyama $M$, lizuka $\mathrm{H}$ : Sequential reorganization of cornified cell keratin filaments involving filaggrin-mediated compaction and keratin 1 deimination. $J$ Invest Dermatol 2002, 118:282-287.

11. Pritzker LB, Nguyen TA, Moscarello MA: The developmental expression and activity of peptidylarginine deiminase in the mouse. Neurosci Lett 1999, 266:161-164.

12. Moscarello MA, Pritzker L, Mastronardi FG, Wood DD: Peptidylarginine deiminase: a candidate factor in demyelinating disease. $J$ Neurochem 2002, 81:335-343.

13. Rogers G, Winter B, McLaughlan C, Powell B, Nesci T: Peptidylarginine deiminase of the hair follicle: characterization, localization, and function in keratinizing tissues. J Invest Dermatol 1997, 108:700-707.

14. Takahara H, Okamoto H, Sugawara K: Specific modification of the functional arginine residue in soybean trypsin inhibitor (Kunitz) by peptidylarginine deiminase. J Biol Chem 1985, 260:8378-8383.

15. Kubilus J, Waitkus RF, Baden HP: Partial purification and specificity of an arginine-converting enzyme from bovine epidermis. Biochim Biophys Acta 1980, 615:246-251.

16. Inagaki M, Takahara H, Nishi Y, Sugawara K, Sato C: Ca2+-dependent deimination-induced disassembly of intermediate filaments involves specific modification of the amino-terminal head domain. $J$ Biol Chem 1989, 264:18119-18127.

17. Takahara H, Tsuchida M, Kusubata M, Akutsu K, Tagami S, Sugawara K: Peptidylarginine deiminase of the mouse. Distribution, properties, and immunocytochemical localization. J Biol Chem 1989, 264:13361-13368.

18. Asaga $H$, Nakashima K, Senshu T, Ishigami A, Yamada M: Immunocytochemical localization of peptidylarginine deiminase in human eosinophils and neutrophils. J Leukoc Biol 2001, 70:46-51

19. Chang X, Yamada R, Suzuki A, Sawada T, Yoshino S, Tokuhiro S, Yamamoto $\mathrm{K}$ : Localization of peptidylarginine deiminase 4 (PADI4) and citrullinated protein in synovial tissue of rheumatoid arthritis. Rheumatology 2005, 44:40-50
20. György B, Tóth E, Tarcsa E, Falus A, Buzás El: Citrullination: a posttranslational modification in health and disease. Int J Biochem Cell Biol 2006, 38:1662-1677

21. Anzilottia C, Pratesia F, Tommasia C, Migliorini P: Peptidylarginine deiminase 4 and citrullination in health and disease. Autoimmunity Reviews 2010, 9:158-160.

22. Agrawal S, Misra R, Aggarwal A: Autoantibodies in rheumatoid arthritis: association with severity of disease in established RA. Clin Rheumatol 2007, 26:201-204.

23. Alivernini S, Fedele AL, Cuoghi I, Tolusso B, Ferraccioli G: Citrullination: the loss of tolerance and development of autoimmunity in rheumatoid arthritis. Reumatismo 2008, 60:85-94.

24. Suzuki A, Yamada R, Chang X, Tokuhiro S, Sawada T, Suzuki M, Nagasaki M, Nakayama-Hamada M, Kawaida R, Ono M, Ohtsuki M, Furukawa H, Yoshino S, Yukioka M, Tohma S, Matsubara T, Wakitani S, Teshima R, Nishioka Y, Sekine K, lida A, Takahashi A, Tsunoda T, Nakamura Y, Yamamoto K: Functional haplotypes of PADI4, encoding citrullinating enzyme peptidylarginine deiminase 4 , are associated with rheumatoid arthritis. Nat Genet 2003, 34:395-402.

25. Chang X, Zhao Y, Sun S, Zhang Y, Zhu Y: The Expression of PADI4 in Synovium of Rheumatoid Arthritis. Rheumatology International 2009, 29:1411-1416

26. Mastronardi FG, Wood DD, Mei J, Raijmakers R, Tseveleki V, Dosch HM, Probert L, Casaccia-Bonnefil P. Moscarello MA: Increased Citrullination of Histone $\mathrm{H} 3$ in Multiple Sclerosis Brain and Animal Models of Demyelination: A Role for Tumor Necrosis Factor-Induced Peptidylarginine Deiminase 4 Translocation. The Journal of Neuroscience 2006, 26:11387-11396

27. Ishigami A, Ohsawa T, Hiratsuka M, Taguchi H, Kobayashi S, Saito Y, Murayama S, Asaga H, Toda T, Kimura N, Maruyama N: Abnormal accumulation of citrullinated proteins catalyzed by peptidylarginine deiminase in hippocampal extracts from patients with Alzheimer's disease. J Neurosci Res 2005, 80:120-128.

28. Bhattacharya SK, Crabb JS, Bonilha VL, Gu X, Takahara H, Crabb JW: Proteomics implicates peptidyl arginine deiminase 2 and optic nerve citrullination in glaucoma pathogenesis. Invest Ophthalmol Vis Sci 2006, 47:2508-25014

29. Bhattacharya SK, Bhat MB, Takahara H: Modulation of Peptidyl Arginine Deiminase 2 and Implication for Neurodegeneration. Curr Eye Res 2006, 31:1063-10671.

30. Rickles FR, Patierno S, Fernandez PM: Tissue factor, thrombin, and cancer. Chest 2003, 124:58-68

31. Chang X, Han J: Expression of Peptidylarginine Deiminase Type 4 (PAD4) in Various Tumors. Molecular Carcinogenesis 2006, 45:183-196.

32. Chang $X$, Han J, Pang L, Zhao Y, Yang Y, Shen Z: Increased PADI4 expression in blood and tissues of patients with malignant tumors. BMC Cancer 2009 9:40.

33. LV Y, Xia Y, Wang Y, Cai C: Expression of PADI4 in hepatocellular carcinoma. The Chinese-German Journal of Clinical Oncology 2009, 8:453-455

34. Stacey SN, Gudbjartsson DF, Sulem P, Bergthorsson JT, Kumar R, Thorleifsson G, Sigurdsson A, Jakobsdottir M, Sigurgeirsson B, Benediktsdottir KR, Thorisdottir K, Ragnarsson R, Scherer D, Rudnai P, Gurzau E, Koppova K, Höiom V, Botella-Estrada R, Soriano V, Juberías P, Grasa M, Carapeto FJ, Tabuenca P, Gilaberte Y, Gudmundsson J, Thorlacius S, Helgason A, Thorlacius T, Jonasdottir A, Blondal T, Gudjonsson SA, Jonsson GF, Saemundsdottir J, Kristjansson K, Bjornsdottir G, Sveinsdottir SG, Mouy M, Geller F, Nagore E, Mayordomo Jl, Hansson J, Rafnar T, Kong A, Olafsson JH, Thorsteinsdottir U, Stefansson K: Common variants on $1 \mathrm{p} 36$ and $1 \mathrm{q} 42$ are associated with cutaneous basal cell carcinoma but not with melanoma or pigmentation traits. Nature Genetics 2008, 40:1313-1318

35. Engelhardt M, Lubbert M, Guo Y: CD34(+) or CD34(-): which is the more primitive? Leukemia 2002, 16:1603-1608.

36. Jackson KA, Majka SM, Wulf GG, Goodell MA: Stem cells: a minireview. Cell Biochem 2002:1-6.

37. Ruff MR, Pert CB: Small cell carcinoma of the lung:macrophage-specific antigens suggest hemopoietic stem cell origin. Science 1984, 225:1034-1036

38. Bongiovanni M, Viberti L, Pecchioni C, Papotti M, Thonhofer R, Hans Popper H, Sapino A: Steroid hormone receptor in pleural solitary fibrous 
tumours and CD34+ progenitor stromal cells. J Pathol 2002 198:252-257.

39. Nakayama H, Enzan H, Miyazaki E, Kuroda N, Naruse K, Kiyoku H, Toi M, Hiroi M: CD34 positive stromal cells in gastric adenocarcinomas. J Clin Pathol 2001, 54:846-848.

40. Sell S: Cellular origin of hepatocellular carcinomas. Semin Cell Dev Biol 2002, 13:419-424.

41. Nakayama H, Enzan H, Yamamoto M, Miyazaki E, Hidaka C, Okumichi T, Okumichi A, Kajihara H: CD34-positive stromal cells in primary lung carcinomas. Oncol Rep 2003, 10:1313-1316.

42. Kuroda N, Toi M, Nakayama H, Miyazaki E, Yamamoto M, Hayashi Y, Hiroi $M$, Enzan H: The distribution and role of myofibroblasts and CD34positive stromal cells in normal pancreas and various pancreatic lesions. Histol Histopathol 2004, 19:59-67.

43. Strobel ES, Strobel HG, Bross KJ, Winterhalter B, Fiebig HH, Schildge JU, Lohr GW: Effects of human bone marrow stroma on the growth of human tumor cells. Cancer Res 1989, 49:1001-1007.

44. Hellwig SM, Damen CA, van Adrichem NP, Blijham GH, Groenewegen G, Griffioen AW: Endothelial CD34 is suppressed in human malignancies: role of angiogenic factors. Cancer Lett1 1997, 20:203-211.

45. Mirza A, Wu Q, Wang L, McClanahan T, Bishop WR, Gheyas F, Ding W, Hutchins B, Hockenberry T, Kirschmeier P, Greene JR, Liu S: Global transcriptional program of $\mathrm{p} 53$ target genes during the process of apoptosis and cell cycle progression. Oncogene 2003, 22:3645-3654.

46. Zuckerman V, Wolyniec K, Sionov RV, Haupt S, Haupt Y: Tumour suppression by p53: the importance of apoptosis and cellular senescence. J Pathol 2009, 219:3-15.

47. Qin H, Yu T, Qing T, Liu Y, Zhao Y, Cai J, Li J, Song Z, Qu X, Zhou P, Wu J, Ding M, Deng H: Regulation of Apoptosis and Differentiation by $\mathrm{p} 53$ in Human Embryonic Stem Cells. J Biol Chem 2006, 282:5842-5852.

48. Qian H, Wang T, Naumovski L, Lopez CD, Brachmann RK: Groups of p53 target genes involved in specific $\mathrm{p} 53$ downstream effects cluster into different classes of DNA binding sites. Oncogene 2002, 21:7901-7911.

49. Kaneshiro K, Tsutsumi S, Tsuji S, Shirahige K, Aburatani H: An integrated map of $\mathrm{p} 53$-binding sites and histone modification in the human ENCODE regions. Genomics 2007, 89:178-188.

50. Yao H, Li P, Venters BJ, Zheng S, Thompson PR, Pugh BF, Wang Y: Histone Arg modifications and p53 regulate the expression of OKL38, a mediator of apoptosis. J Biol Chem 2008, 283:20060-20068.

51. Li P, Yao H, Zhang Z, Li M, Luo Y, Thompson PR, Gilmour DS, Wang Y: Regulation of $\mathrm{p} 53$ target gene expression by peptidylarginine deiminase. Mol Cell Biol 2008, 28:4745-4758.

52. Hagiwara T, Hidaka $\mathrm{Y}$, Yamada M: Deimination of Histone $\mathrm{H} 2 \mathrm{~A}$ and $\mathrm{H} 4$ at Arginine 3 in HL-60 Granulocytes. Biochemistry 2005, 44:5827-5834.

53. Cuthbert GL, Daujat S, Snowden AW, Erdjument-Bromage H, Hagiwara T, Yamada M, Schneider R, Gregory PD, Tempst P, Bannister AJ, Kouzarides T: Histone deimination antagonizes arginine methylation. Cell 2004, 118:545-553.

54. Liu G, Liao Y, Chang W, Liu C, Hsieh M, Hsu P, Tsay G, Hung H: Overexpression of peptidylarginine deiminase IV features in apoptosis of haematopoietic cells. Apoptosis 2006, 11:183-96.

55. Chu $P G$, Weiss $L M$ : Keratin expression in human tissues and neoplasms. Histopathology 2002, 40:403-439.

56. Barak V, Goike H, Panaretakis KW, Einarsson R: Clinical utility of cytokeratins as tumor markers. Clin Biochem 2004, 37:529-540.

57. Omary MB, Ku NO, Liao J, Price D: Keratin modifications and solubility properties in epithelial cells and in vitro. Subcell Biochem 1998, 31:105-140.

58. Edoute Y, Haim N, Rinkevich D, Brenner B, Reisner SA: Cardiac valvular vegetations in cancer patients: a prospective echocardiographic study of 200 patients. Am J Med 1997, 102:252-258.

59. Chang X, Yamada R, Sawada T, Suzuki A, Kochi Y, Yamamoto K: The inhibition of antithrombin by peptidylarginine deiminase 4 may contribute to pathogenesis of rheumatoid arthritis. Rheumatology 2005, 44:293-298

60. Ordóñez A, Martínez-Martínez I, Corrales FJ, Miqueo C, Miñano A, Vicente $\checkmark$, Corral J: Effect of citrullination on the function and conformation of antithrombin. FEBS 2009, 276:6763-6772.

61. Maragoudkis ME, Tsopanoglou NE, Andriopoulou P: Mechanism of thrombin induced angiogenesis. J Biochem Soc Trans 2002, 30:173-177.
62. Pan C, Shen Z, Wu T, Tang X, Wang M, Sun J, Shao Y: Cell adhesion to fibronectin induces mitomycin $\mathrm{C}$ resistance in bladder cancer cells. BJU Int 2009, 104:1774-1779.

63. Bandyopadhyay A, Raghavan S: Defining the role of integrin alphavbeta6 in cancer. Curr Drug Targets 2009, 10:645-652.

64. Chang X, Yamada R, Suzuki A, Kochi Y, Sawada T, Yamamoto K. Citrullination of fibronectin in rheumatoid arthritis synovial tissue. Rheumatology 2005, 44:1374-1382.

65. Dong S, Zhang Z, Takahara H: Estrogen-Enhanced peptidylarginine deiminase type IV Gene (PADI4) expression in MCF-7 cells is mediated by estrogen receptor-a-promoted transfactors activator protein-1, nuclear factor-Y and sp1. Mol Endocrinol 2007, 21:1617-1629.

66. Tanikawa C, Ueda K, Nakagawa H, Yoshida N, Nakamura Y, Matsuda K: Regulation of Protein Citrullination through p53/PADI4 Network in DNA Damage Response. Cancer research 2009, 69:8761-8769.

doi: $10.1186 / 1475-2867-10-7$

Cite this article as: Chang and Fang, PADI4 and tumourigenesis Cancer Cell International 2010, 10:7

\section{Submit your next manuscript to BioMed Centra and take full advantage of:}

- Convenient online submission

- Thorough peer review

- No space constraints or color figure charges

- Immediate publication on acceptance

- Inclusion in PubMed, CAS, Scopus and Google Scholar

- Research which is freely available for redistribution

Submit your manuscript at www.biomedcentral.com/submit
C BioMed Central 